\title{
New interpretation to Burckhardt, 1961 and Aldelaimi, 1991 measurements of oil well surge and swab pressures graphical comparison.
}

\author{
Dr. Shallal N. Mahdi \\ AL-Farabi University College \\ Email: Aldelaimi.shallal@yahoo.com \\ DOI: $10.31364 / S C I R J / v 7.19 .2019 . P 0919701$ \\ http://dx.doi.org/10.31364/SCIRJ/v7.i9.2019.P0919701
}

\begin{abstract}
Positive (Surge) and negative (Swab) pressures due to pipe movement down and up hole of oil and wells have a great influences on well stability and well security, for economical and well stability risks danger(Reservoirs petroleum intrusion in to the well bore) as fields studies confirm, since Cannon, 1934 till now.
\end{abstract}

Burckhardt's real symbolic measurements (unique curve) 1961, with his approach to explain the physical cause, nature and magnitude of these phenomena by calculation based on Bingham's fluid flow regime(Rheological model) has miss led many authors later on, as being considered as standard symbolic example.

This paper, with the aid of Aldelaimi non published laboratory measurements and curves, 1991 a new review and analysis to Burckhardt's approach and unique curve has showed that his chart is not only a general behavior form of surge and swab, but it is a single case curve.

A New Analysis and point of view on his work is presented in this paper to explain and uncover the more complexity of these phenomena, where what so called "the Clinging Factor" is cloudy and more complex than proposed treatments as in many literatures. Same as that maximum mud displaced velocity, rheology and some other parameters.

Introduction: The importance of surge and swab pressures while what called round trips or casing running in hole, in other meaning pipe movement in the well(drill pipes, casing, others), cause Surge and Swab pressures is of great influence on well stability and well security.

Surge pressure may break weak formations under high compressive pressure and drilling mud can be lost (mud losses), while in the second, well bore can be swabbed, where formation fluids (oil and or gas) can be produced into the well bore. In all, blow outs unfortunately may drive to expose the well to serious situations or risk the security of that oil and gas wells.

Many studies on surge and swab pressures were published since Cannon, 1934 (7) and Melrose et al 1958(6), with many assumptions to explain the physical cause, nature and magnitude of these phenomena, where very rare to find those ones based on real field or simulated laboratory direct well measurements.

In 1961, Burkhardt's real measurements unique representation (2), with his approach of calculation based on Bingham's fluid flow regime (Rheological model) has miss led many authors later on, as being considered as standard symbolic example.

Later on, in 1991, with the aid of a well simulator, Aldelaimi Sh. N. M., (4), had made a wide laboratory measurements and curves for different parameters influencing, mainly:types of drilling muds, which are in reality neither :Binghamian" fluid type nor "Ostwaldian" type but almost in between.

This paper is then making use of data from previous measurements in order to benefit at least a qualitative analysis of this phenomena.

Thus a new review and analysis to Burkhardt's unique measurement has showed that his graph of measurement although it is unique, it is a particular field practice (Certain casing joint running style) to induce surge and swab pressures, but it is only a single case curve.

This work has made use of several non published data concerning the previously mentioned parameters.

\section{Short theoretical Review :}

Qualitative and quantitative achievements of Burkhardt's approach of defining surge and swab pressures due to pipe movement in a hole filled of drilling mud, rests the most comprehensive steady state case work on static surge and swab pressures, since the early attempts to understand this phenomena.

The effective reason for this phenomena, is related mainly to the gel tendency or resistance of mud and to the drilling mud viscosity in the moving pipe, hole or casing to the down or up movement of that pipe.

The gel resistance can be measured directly by rheometrs, while the mud velocity of fluid may be determined from the rational volumetric displacements of mud in the pipe and in the annulus between the two pipes (annular space). 
The displaced mud velocity is also depends greatly on the velocity of moving pipe upward or down word, which is the major factor to produce swab or surge pressures respectively.

This displacement of mud along the length of moving pipe has its maximum pressure effect on bottom of that pipe and below, while it is a decreasing value up word towards the surface.

Formulation of these pressures has been based and presented by same way and by many authors either by field units(British System Units) or standard research units(Metric or French system) same way as pressure losses calculations for laminar and turbulent flows.

Burkhardt J.A. (1961) and Aldelaimi Sh.N.(1991)had followed the same theoretical assumptions of previous authors(Clark,1954 and Melrose,1958 and others) as what concern above and whether the end of moving pipe is opened or fully closed.

This paper is trying to critic some assumptions to look after new revision and analysis with a new point of view about the old historic assumptions, that by matching those old measures to show the importance of the annular clearance between moving pipe and the hole or surrounding casing, also the speed and depth or length of moving pipe.

More over the complexity of these phenomena, where what so called " Clinging " is more complex than the simple proposed one, as for Simple Bingham mud or the Newtonian fluids in most of literatures,(see Figs.1 and 2).

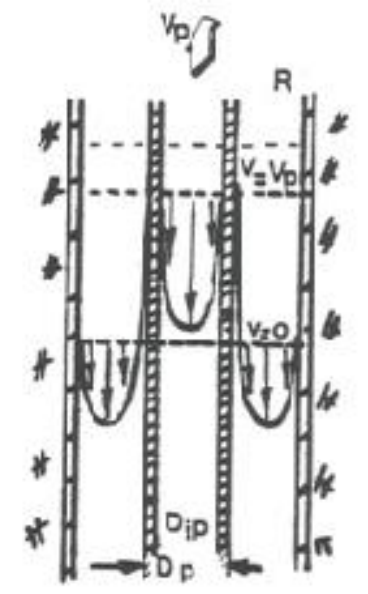

timin + A. 0

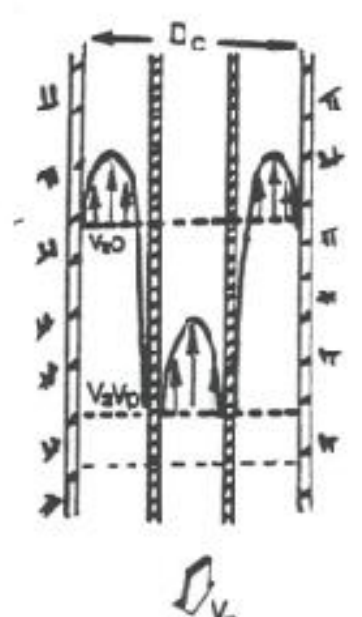

Fig.( 1): Schematic representation of direction of pipe movement, fluid displacements and Clinging factor influence respectively. Note:The Clinging factor "K"has another definition as the moving pipe proportionality factor with respect to hole or casing diameter.

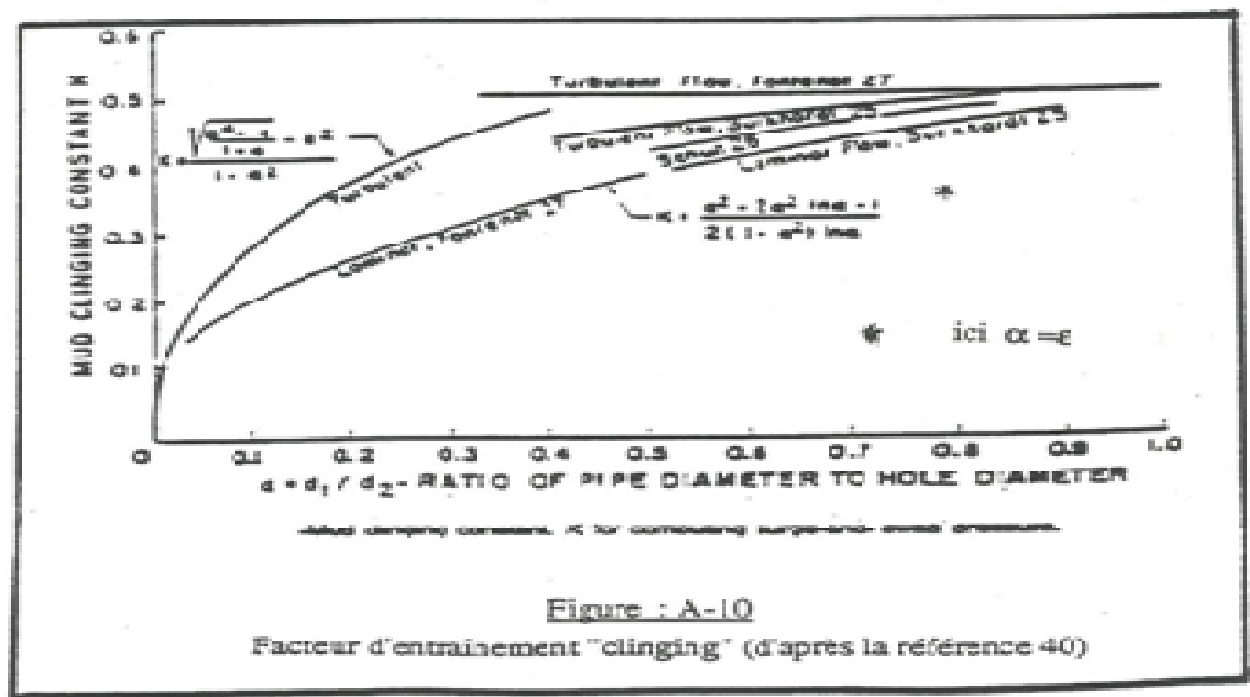

Fig.(2): Influence of clinging factor(After ref.4 and 10)

Many authors believe that pipe movement down and up hole has two components of mud velocity: one is due to clinging of mud on surface of moving pipe and the other due to the viscosity of mud

Equation(1) is to calculate pressure of mud gel breaking (T) along the pipes depth( 1 ), where Dh and Dp are diameters of hole and moving pipe respectively( It is obviously to mention that we are considering a simplified approach in field units as follows: 
(1)

$$
P=\frac{1 \tau}{300\left(D_{h}-D_{p}\right)}
$$

Equation(1)Calculation of pressure $\mathrm{P}$ to break all gel along depth of moving pipe of diameter Dp down hole of diameter Dh in field units.

$$
\mathrm{K}=0.45
$$

$$
\mathrm{v}=\left[\mathrm{K}+\frac{\mathrm{D}_{\mathrm{p}}^{2}}{\mathrm{D}_{\mathrm{h}}{ }^{2}-\mathrm{D}_{\mathrm{p}}{ }^{2}}\right] \mathrm{v}_{\mathrm{p}}
$$

Equation(3)Closed pipe two components of mud velocity representing the effective velocity.

Equation(4)Opened pipe case of the two components of mud effective velocity, where Di is interior diameter of moving pipe

$$
V=\left[\mathbf{K}+\frac{\mathbf{D}_{\mathrm{p}}{ }^{2}-\mathbf{D}_{\mathrm{i}}{ }^{2}}{\mathbf{D}_{\mathrm{h}}{ }^{2}-\mathbf{D}_{\mathrm{p}}{ }^{2}+\mathbf{D}_{\mathrm{i}}{ }^{2}}\right] \mathbf{V}_{\mathrm{p}}
$$

$$
v_{m}=1.5 \mathrm{~V}
$$

Equation(5) Estimation of maximum mud velocity as one and half of plastic velocity.

Equations (6) and (7)below respectivly are :

$$
\begin{gathered}
P_{s}=\frac{(P V) v m l}{60,000\left(D_{h}-D_{p}\right)^{2}}+\frac{y l}{200\left(D_{h}-D_{p}\right)} \\
P_{s}=\left[\left(\frac{2.4 v_{m}}{D_{h}-D_{p}}\right)\left(\frac{2 n+1}{3 n}\right)\right]^{n} \frac{K l}{300\left(D_{h}-D_{p}\right)}
\end{gathered}
$$
..(6),(7)

to calculate Surge and swab pressures Ps for laminar mud flow for Bingham and Ostwald "Power law", respectively.

Equation(8) Calculation of

$$
\mathrm{P}_{\mathrm{s}}=\frac{7.7\left(10^{-5}\right) \rho^{.8} \mathrm{Q}^{1.8}(\mathrm{PV})^{\cdot 2} 1}{\left(\mathrm{D}_{\mathrm{h}}-\mathrm{D}_{\mathrm{p}}\right)^{3}\left(\mathrm{D}_{\mathrm{h}}+\mathrm{D}_{\mathrm{p}}\right)^{1.8}}
$$

surge and swab pressures for turbulent mud flow case.( Noting that parameters are in field units). 

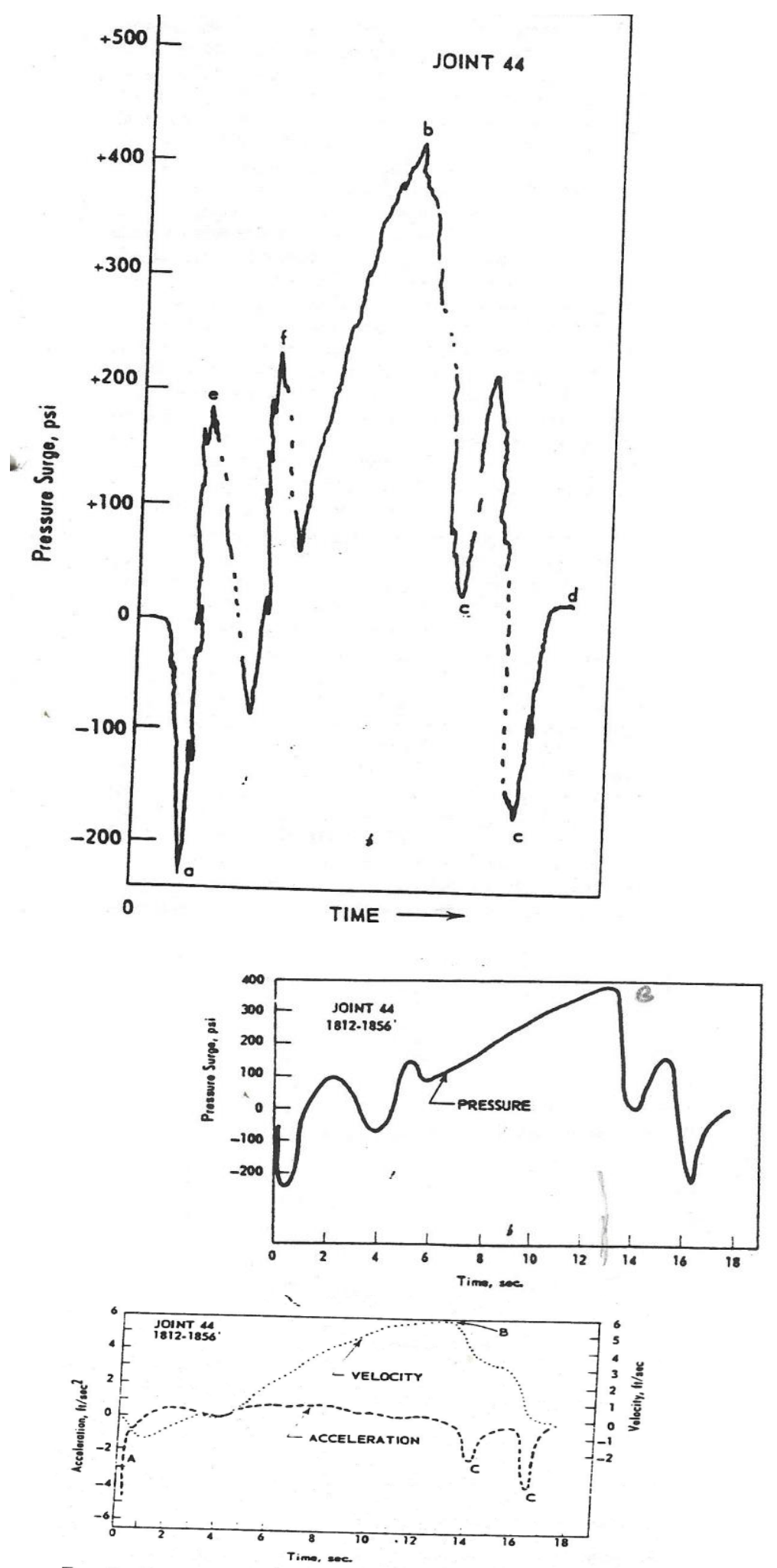

(Fig.(3a,3b and 3c from above respectively)

Comparison of Burckhardt's measured and calculated surge and swab pressures with speed and acceleration

\section{Burkhardt 's measurements of surge and swab pressures:}

Burkhardt surge and swab pressures measurements has used a single joint of casing pipe to be added to a string of casing , where it included only one sensor measurement, which is apparently at the end of the moving pipe bath or at the bottom of the well under this measurement test Fig.(3a). 
He assumed that about half a joint length to be run with accelerating gradual speed (Fig.3b), till its maximum value, then deceleration(Fig.3c), till holding the string on the slips.

One can notice pressure fluctuation due to the vibration of pipe after lifting up the string point(a), then before reaching maximum speed (b)and after till setting the string on the rotary table slips(c).

Assumptions and considerations has Burkhardt applied: Burkhardt has made or followed many other authors' assumptions and considerations, we mention some of them:

1)Surge pressure is equal to Swab pressure.

2)Using Bingham type of drilling mud or Newtonian fluids.

3)Annular space between pipes is not always as parallel plates assumption.

4)Using Fanning equation of Newtonian fluids to calculate pressures.

5)Drilling or casing strings are considered as completely closed is not valid..

6)Influence of inertia is not properly estimated.

7)Assuming of hole well filled in practice, sometimes is not valid.

8)Mud flow regime is not always identical to that of Newtonian fluids.

9)Assumption of maximum speed of mud to be 1.5 the effective velocity has no justification.

10)Clinging factor as to be $\mathbf{0 . 4 5}$ in calculating clinging component of effective mud velocity is not properly justified as well.

\section{$\underline{\text { Aldelaimi's Measurements of surge and swab pressures: }}$}

Many measurement conditions were applied not only to have laboratory measures of the phenomena but to test for the influence of many parameters.

The apparatuses used are well components as a well simulator with three sizes of moving pipes $(.0762 \mathrm{~m}, 0.0623 \mathrm{~m}$ and $0.0423 \mathrm{~m})$ with interior sizes of $(0.07 \mathrm{~m},, 0.045$ and closed $)$. Three velocities of moving pipes: $0.1 \mathrm{~m} / \mathrm{s}, 0.2 \mathrm{~m}$ and $0.3 \mathrm{~m} / \mathrm{s})$. Some of them are shown in figures from 4 to 9 , with fluids types as indicated as follows:

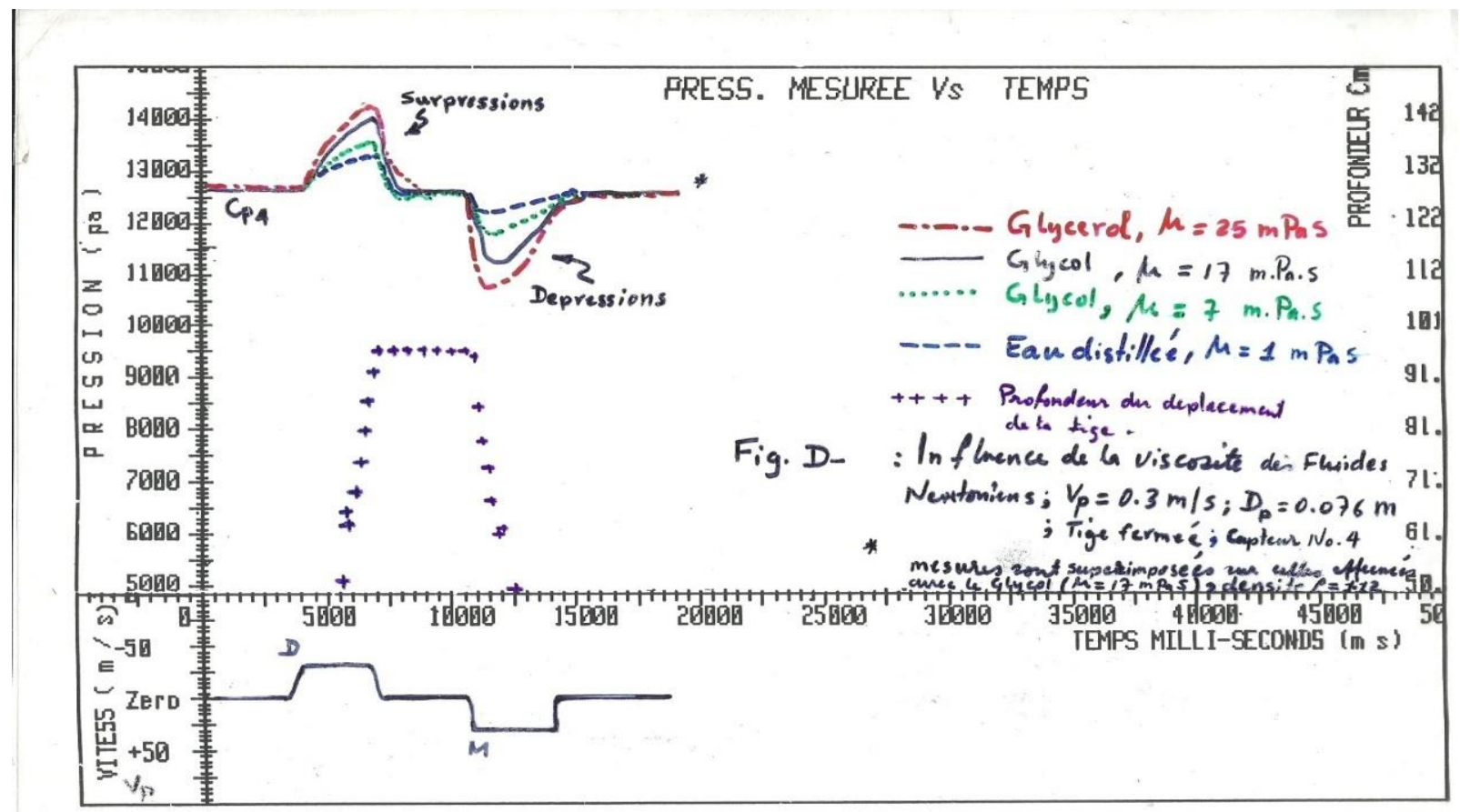

Fig.(4): Some ideal measures of surge and swab pressures, where the fluid is Glycol, which is Newtonian type to check for the viscosity influence. Here we mention that surge and swab pressures are not identical.(Noting that time is measured by milliseconds as in the velocity field of the schematic representing) 


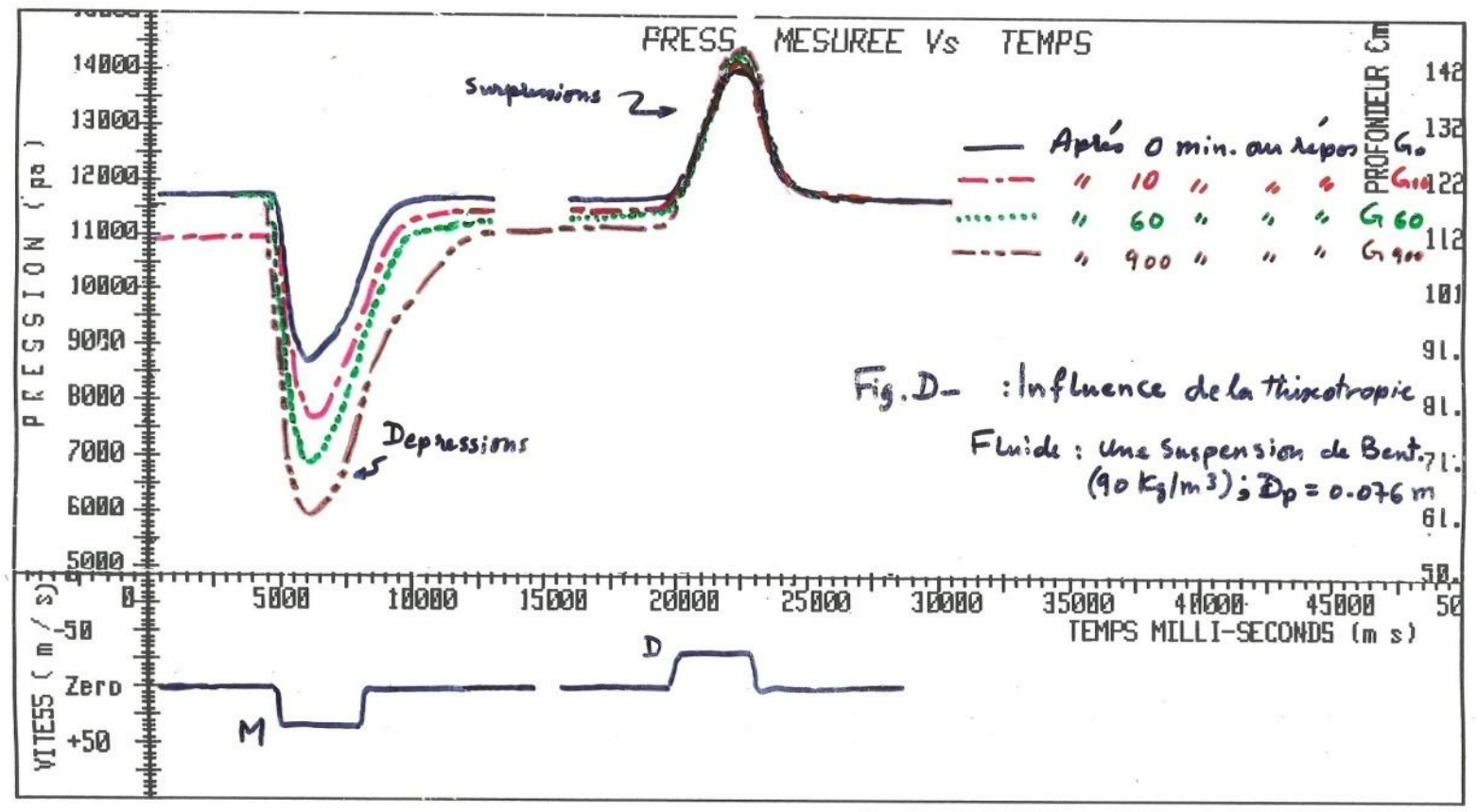

$\underline{\text { Fig(5): }}:$ Influence of gel on swab pressures is remarkable higher than surge pressures with constant mud type and moving pipe.

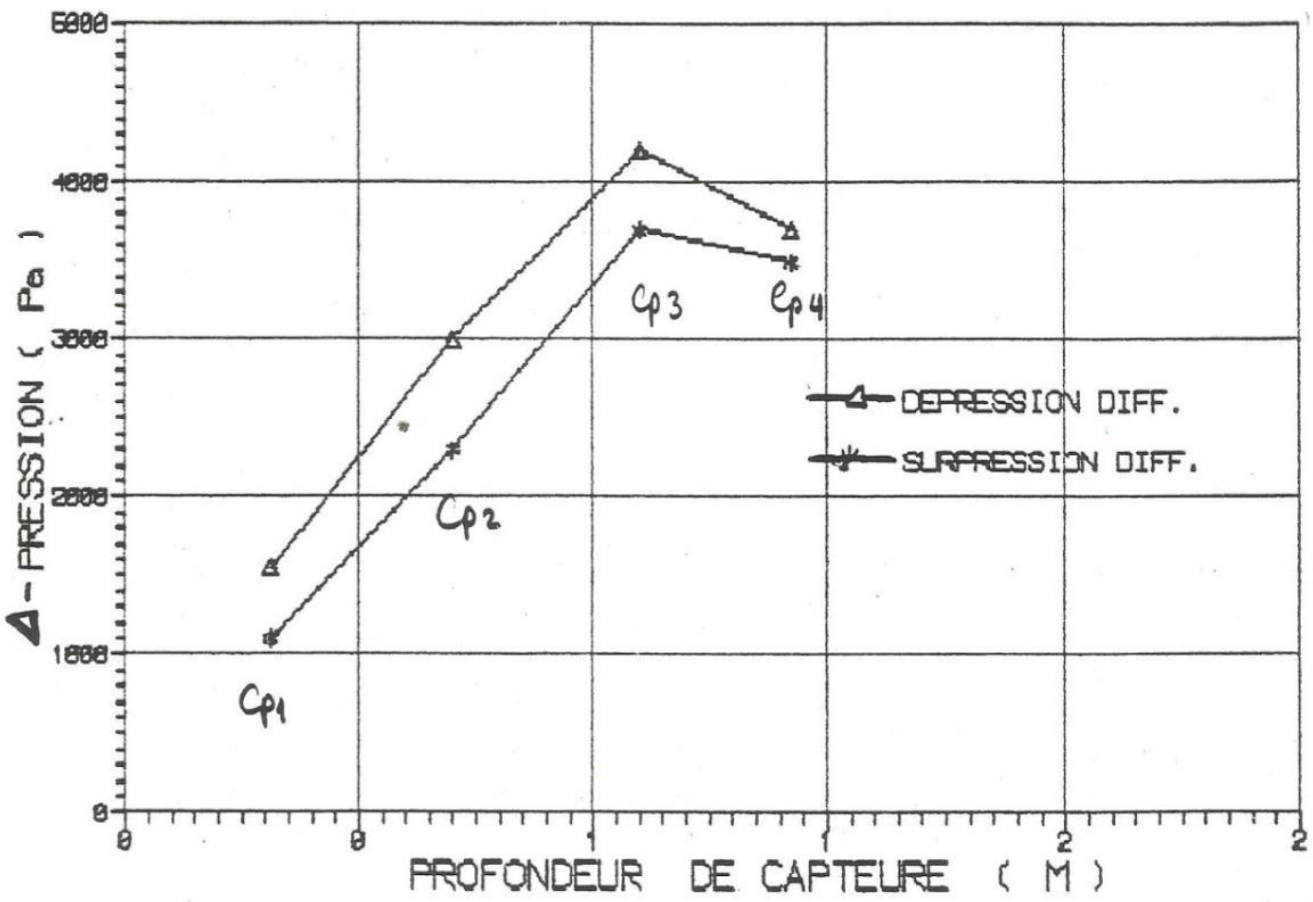

Fig.(6): Influence of depth of sensor down the hole, where the swab pressure is also higher than surge pressure. 


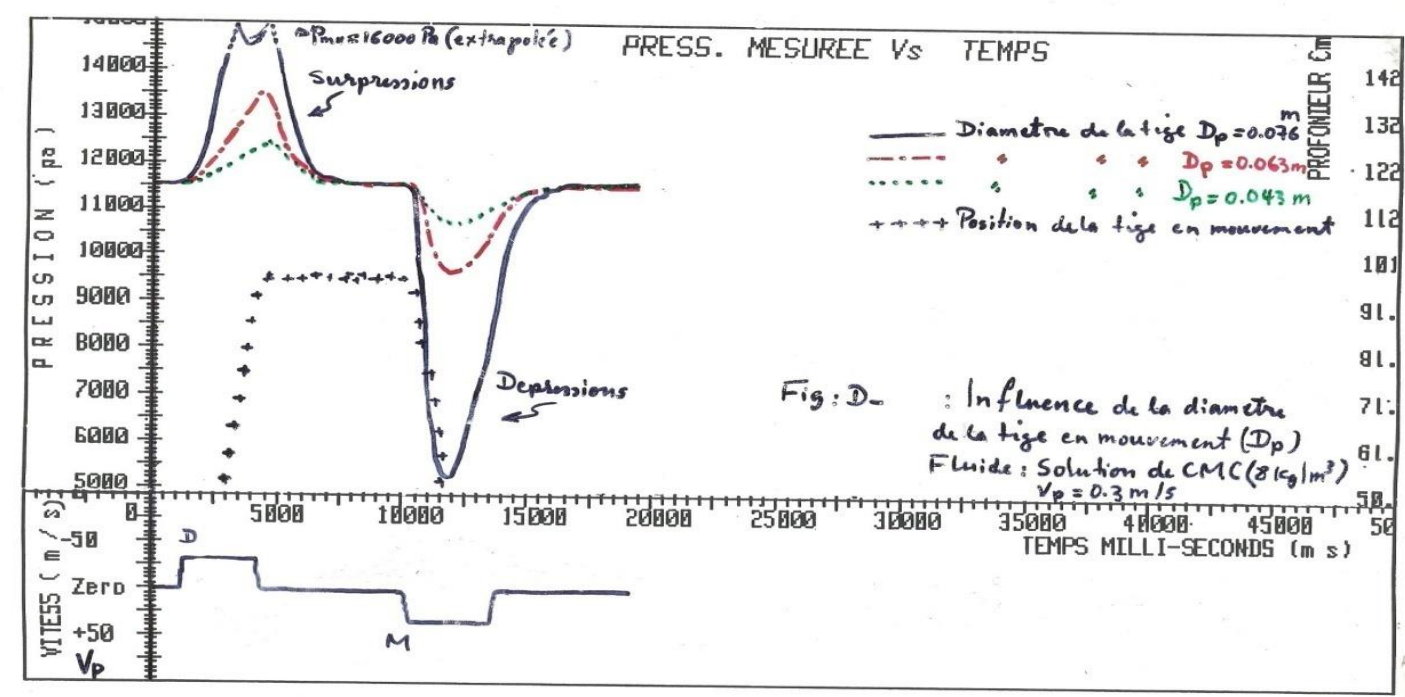

diameter of moving pipe on surge and swab pressures for same pipe velocity.

Fig.(7): Influence of

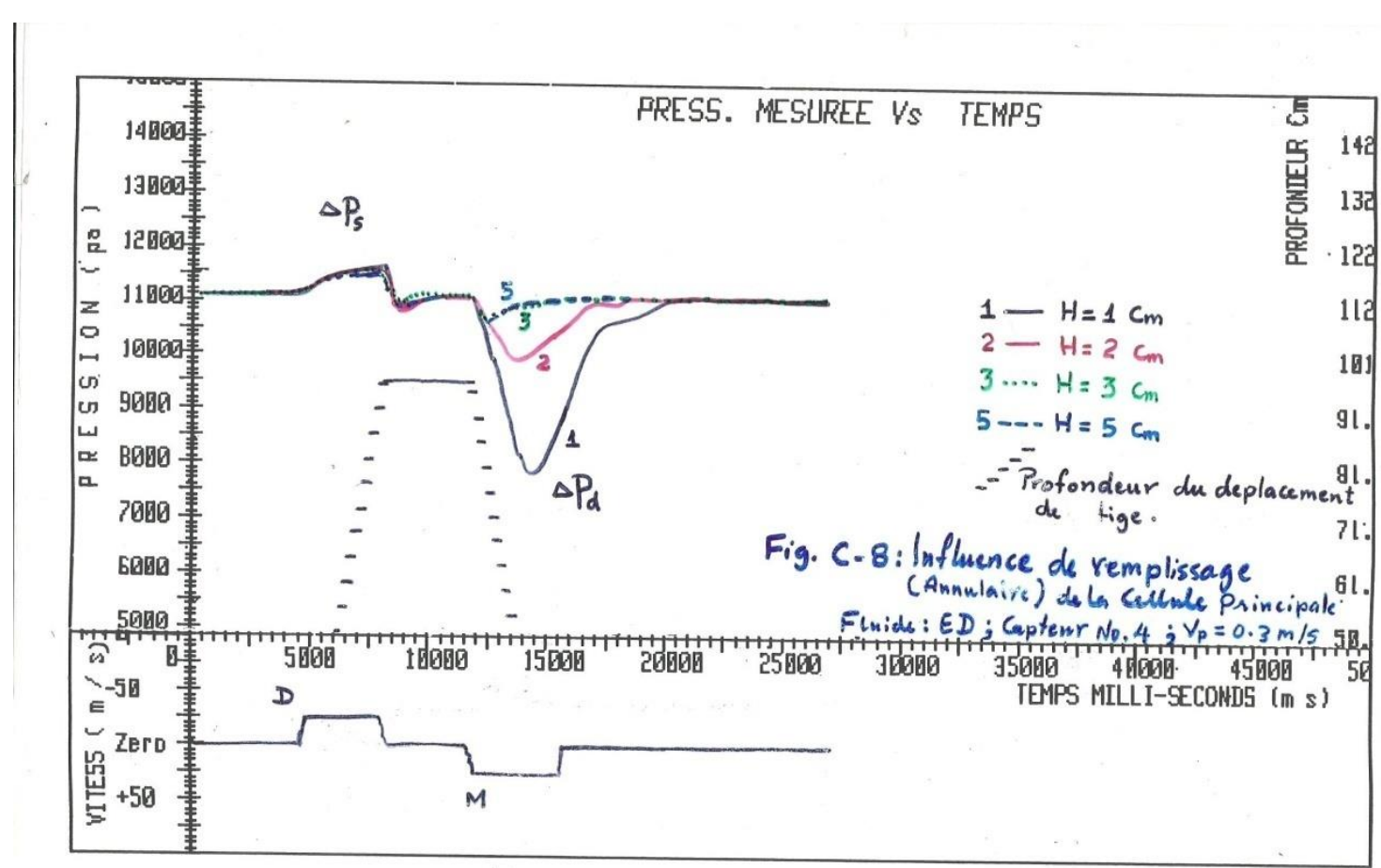

Fig.(8): Influence of filling of hole on swab pressures, which is significant. 


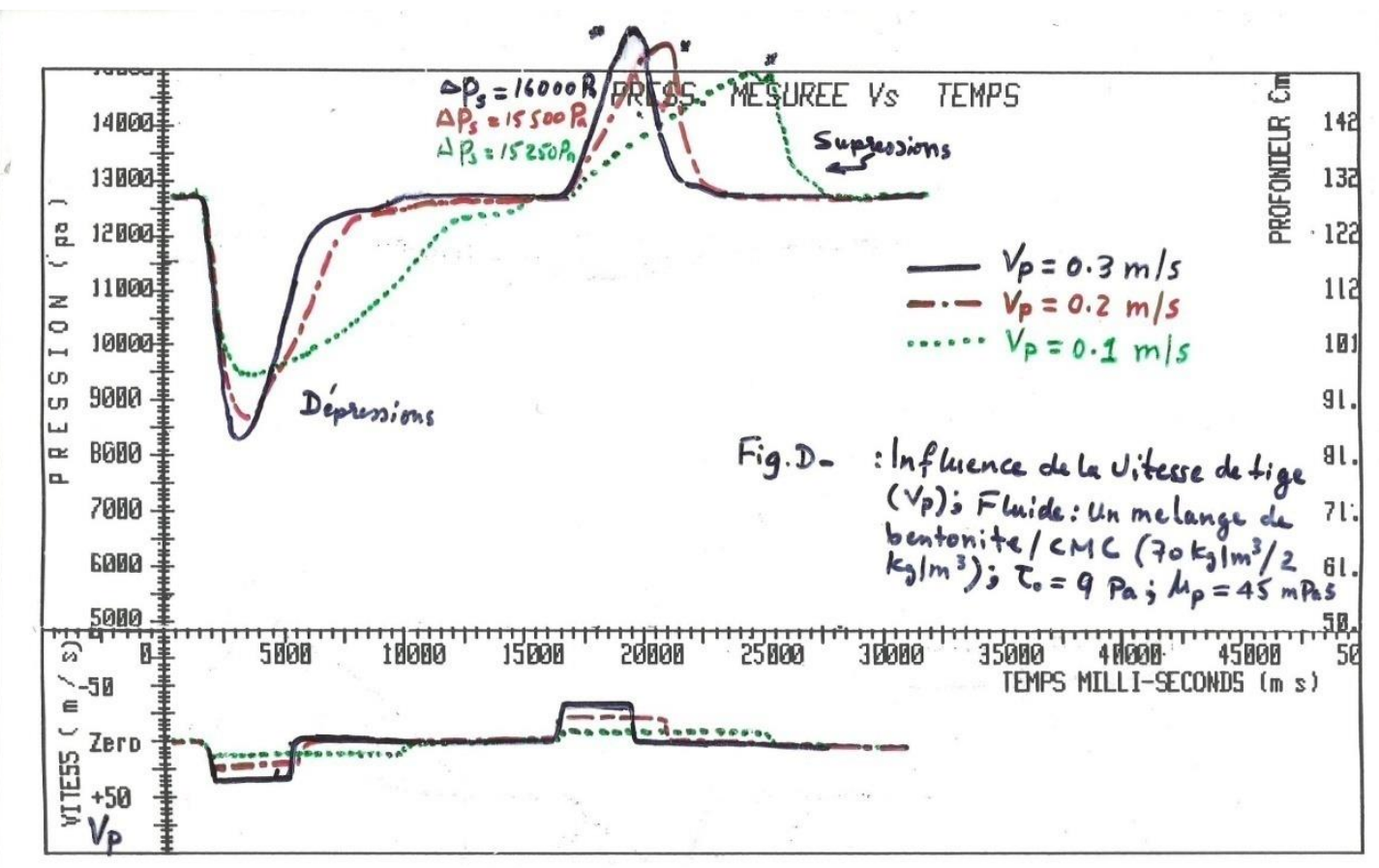

Fig.(9): Influence of the pipe velocity on surge and swab pressures, profiles and peaks are remarkable.

\section{Qualitative analysis between the two types of measurements:}

After displaying and discussing the theory and parameters influences on surge and swab pressures, we denote here that, although Burkhardt and Aldelaimi are mentioned as they are satisfied by their calculated surge and swab pressures to match to a certain extent the measured values, we mention here that the various parameters and complex influence of those parameters show clear divergence, beside the non matching of surge and swab pressures( see the sensitivity and conduit of curves to the influence parameters on the swab pressure).

This, also confirm the in equality of surge and swab pressures, particularly at high values of parameters.

The numerous assumptions made to simplify the conditions of the phenomena was misleading to the reality and to influence values. Such remarks are existing in clinging factor estimation, which is not constant and its values between 0.4 and 0.5 is meaningless with type of fluids and flow regime since its empirical values are based on Newtonian fluids.

As what concern maximum velocity of the displaced mud has no meaning as mentioned before. Others, like the inertia influence and the rate of filling of the well with respect to depth, gelation, mud weight and viscosity. The divergences mentioned and illustrated by the above figures only laboratory examples. In the field one can see how driller break small jerking effect surge and swab pressure indicated on Burckhardt's unique chart.

\section{Conclusions and advises:}

A bout a century was turned off and the fields operators trying to solve oil and gas complexity and risk of surge and swab pressures phenomena. Operators are not sure yet about sudden surprising risks of lost of circulation, mud kicks and mud damages or even blowouts of oil and/or gas up to the surface.

Studies since then were started by simple tools, hypothesis and assumptions some of them are not justified as proceeded.

Now a days, in the modern effective theoretical and operational tools and equipment, such as sensing, vision, simulation and computing.

It become possible to such facilitations to measure and predict surge and swab pressures a head of time and give warranties to tool pushers and engineers to prevent and to well secure risk of workers and equipments.

Drilling fully automated Rigs are now on service in many countries, where even learned machines and artificial intelligent computing system are used for these purposes.

The younger academic researchers with these new tools, must hold the responsibility to revise and deepen the knowledge by these phenomena theoretically and operationally. 


\section{References:}

1- Clark, E. H. Jr. :" Bottom hole pressure surges while running pipie " Pet. Eng., Jan.1955 ).

2- Burkhardt, J. A. " Wellbore pressure surges produced by pipe movement," J. Pet. Tech., June , 1961 )

3)- Moore P. L. " Pressure surges and their effect on hole condition," Oil and gas J. Dec.,3, 1964 )

4)- Aldelaimi Sh. N. M. " Surpressions et Depressions dans les annulaires des puits petroliers en cours de mannoevres ", Vol.1,Avril.15, 1991)

5)- Melrose J. C. et al " .A practical utilization of the theory of Bingham plastic flow in stationary pipes and annuli," Trans AIME

6) Dodge, et al " Turbulent flow of non-Newtonian systems," AICbF J, 1955", vol5.

7) Cannon, G.E." Changes in hydrostatic pressure due to withdrawing drill pipe from the well, drilling and production practices- 1934", API . 